\title{
THE ASSESSMENT OF INTERMODAL TRANSPORT IN COUNTRIES OF THE DANUBE REGION
}

\author{
Snežana Tadić ${ }^{1}$, Milorad Kilibarda ${ }^{2}$, Milovan Kovač ${ }^{3}$, Slobodan Zečević ${ }^{4}$ \\ 1,2,3,4 University of Belgrade, Faculty of Transport and Traffic Engineering, Vojvode Stepe 305, 11000, \\ Belgrade, Serbia
}

Received 15 October 2020; accepted 14 March 2021

\begin{abstract}
The development of intermodal transport (IT) systems is one of the global and European imperatives with the goal of mitigating logistics activities (especially transportation) negative impact on the environment, but also to improve the efficiency of logistics systems. Despite its importance acknowledged long ago, the treatment of IT greatly varies in different countries. In the developed countries, IT has an institutional character and clearly defined development directions, while in the developing countries, the problems of IT in most cases are ignored. The main scientific contribution of this paper is in being the first one to assess the status of IT in the countries of the Danube region. Seven criteria and six evaluation scenarios, that were not present in the existing literature in this form, are defined, which represents another contribution of the paper. The criteria are defined so that they would include the treatment of IT in strategic documents, the opinions of users and service providers, but also empirical/ statistical indicators of IT development degree. The evaluation scenarios differ in the criteria significance and the aspect of the problem. A novel hybrid multi-criteria decision-making (MCDM) model, based on fuzzy SWARA and fuzzy MARCOS methods, is developed for the assessment, which represents an additional scientific contribution of the paper. According to IT results, the countries are grouped into five categories, micro-regions. The results indicate that with the degree of economic development the status of IT improves as well, so Germany and Austria are leading, followed by the Czech Republic, then by countries such as Hungary, Slovenia and Slovakia, while other countries fall behind greatly.
\end{abstract}

Keywords: intermodal transport, MCDM, Danube region, micro-region, fuzzy, SWARA, MARCOS.

\section{Introduction}

The changes in the structure and volume of intercontinental goods flows, caused by globalization, economic changes and the rise of living standards, individualization and personalization of production and consumption, demographic and political changes, etc., have put the logistics sector under great pressure, especially the transportation subsystem. The dominance of road transportation in the realization of the growing flows has significant negative impacts on the economic, social and environmental sustainability. The traditional approach of developing individual transportation modes is not able to offer sustainable solutions in the realization of intercontinental goods flows for a long time now (Barisiene, 2012). Their realization

\footnotetext{
${ }^{1}$ Corresponding author: s.tadic@sf.bg.ac.rs
} 
can become sustainable only through the integration of different transportation modes with the application of intermodal transport (IT) (Zečević, 2009).

IT represents the transportation of goods in one and the same loading unit or vehicle using multiple transportation modes, without goods transhipment between the transportation modes (ECMT, 2001). Since multiple transportation modes and actors are involved (Caris et al., 2013), IT is characterized by great complexity and the need for adequate, long-term planning, development and maintenance. The developed countries of the world and the EU realized the importance of IT, so the global trend is the modal shift from road transportation on environmentally acceptable transportation modes (rail or inland waterway). The goal of the EU is to shift $30 \%$ of road transportation until 2030 , and $50 \%$ until the year 2050 , on environmentally acceptable transportation modes (EC, 2011). Despite that the EU promotes intermodality, little has been done on the field of comprehensive IT research and planning.

To improve the participation of IT in the overall transportation, it is necessary to define the responsible actors and institutions, to ensure cooperation among all participants in the intermodal chain, to plan and design terminal networks, to ensure the competitiveness of intermodal prices and services, to research and keep track of goods flows realization trends, to develop necessary technologies, etc. (Tadić \& Zečević, 2012). Despite that the key problems of IT are acknowledged in the existing research, a comprehensive and interdisciplinary approach for the planning and development of the European IT system is still absent (Eftestöl-Wilhelmsson et al., 2014). Although the EU, through the projects such as Pilot Action for Combined Transport (PACT), Marco Polo I, Marco Polo II, etc., attempted to improve the competitiveness of IT, substantial effects of the implemented measures are still absent, while the participation of IT in the overall transportation remains low (Suarez-Aleman et al., 2014).

The main scientific contribution of this paper is in being the first one to analyze the status of IT in the countries of the Danube region, as well as how the set of criteria and evaluation scenarios are defined. The Danube region consists of 14 countries - Germany, Austria, Czech Republic, Slovakia, Hungary, Slovenia, Croatia, Bosnia \& Herzegovina, Montenegro, Serbia, Bulgaria, Romania, Moldova and Ukraine. The countries differ significantly in socio-economic characteristics, problems, development degree, and applied IT technologies, therefore the status of IT is different. The status of IT is assessed according to seven criteria that include the IT treatment in national strategic documents, empirical and statistical data regarding the real status of IT, as well as users' and service providers' qualitative perception of IT. Six evaluation scenarios are defined according to the criteria importance and the aspect of the problem. For the assessment of IT on the national level, a novel hybrid multicriteria decision-making (MCDM) model is developed. The MCDM model is based on the methods Step-wise Weight Assessment Ratio Analysis (SWARA) and Measurement Alternatives and Ranking according to the 
Compromise Solution (MARCOS), in the fuzzy environment, and as such represents another scientific contribution of this research. After the assessment, the countries are ranked and classified into micro-regions. The results indicate that Germany and Austria belong to the category of countries with excellent IT status followed by the Czech Republic, while the other countries fall behind greatly.

The remainder of the paper is organized into 3 sections. The next section describes the criteria and scenarios used for the evaluation of the status of IT in the countries of the Danube region. Section 3 explains in detail the algorithmic steps of the developed hybrid MCDM model, as well as the setup of input parameters for the assessment of IT status in the countries of the Danube region. The results analysis is presented in section 4, which is followed by the section with concluding remarks and future research directions on this topic.

\section{Criteria and Scenarios for the Assessment of IT Status}

For the assessment of the status of IT, the literature identified a large number of criteria. The criteria depend mostly on the stakeholder from whose perspective the problem is observed, but also on the comprehensiveness of the research. EngLarsson \& Kohn (2012) in their research analyze the shippers' attitude towards the modal shift from road transportation to IT, and state that transit time and reliability are the main criteria. In the research (Islam et al., 2016), the authors follow up, and state that the most important criteria, from the shippers' perspective, are costs, service availability, safety and environmental impact. The paper (Van den Berg \& De Langen, 2015) claim that the most important criteria, from the perspectives of shippers and forwarders in the Netherlands, are transit times, the flexibility of service, reliability, costs, while the environmental impact is considered as the least important. Fang et al. (2019) in their research comparatively analyze the IT strategic development plans of China and the United Kingdom, where transit time, reliability, costs, online service, and the application of modern technologies are highlighted as the most important criteria for IT quality assessment. Gharehgozli et al. (2019) in their research state that standardization and harmonization, although insufficiently explored in the literature, greatly impact the service providers' perception of IT quality.

As shown, for the evaluation of the status/ quality of IT, the literature defines different criteria. Furthermore, in most cases the authors analyze the problem only from the aspect of one stakeholder group, or in the case of more stakeholders, they take into account only the perceptions of shippers/ users and forwarders/service providers. To be able to assess the IT status of a country, the criteria in this research are defined to include the aspects of users, service providers, but also the neutral aspect based on the strategic documents of countries and available statistics/empirical data regarding IT (Table 1). In the following text, the criteria for the assessment of IT status in the countries of the Danube region are explained, while depending on the aspect of the problem and the evaluation scenario, some of the criteria are differently interpreted. 
C1 - IT treatment in strategic documents of Danube region countries. This qualitative criterion describes the presence of the IT system in the development plans and other strategic documents according to the number of defined problems, goals, measures/ actions, and the competence/potential of a country to carry out all the defined measures/actions. Different problems of IT are highlighted in the national strategic documents, and some of the most considered are the lack of information-communication technologies, shortage of adequate terminals, obsolescence and shortage of vehicles, institutional frameworks, etc. (Tadić et al., 2018a). Countries such as Germany, Romania, Austria and Slovenia are the leaders in terms of IT treatment in strategic documents. Germany has a defined federal body that covers the problems of logistics, proposes detailed research, defines the development directions, promotes logistics and IT, etc. (FMoTBD, 2010). Romania in its strategic plan of IT development defines necessary interventions based on different scenarios and promotes transportation on the Danube river (AECOM Ingeniera SRL, 2014). Austria also highlights the importance of IT development on the Danube, as well as establishing regular intermodal connections between logistics centres (BMVIT, 2011). Alongside Germany, Slovenia has the most defined goals, measures and indicators regarding IT (Ministry of Infrastructure - Republic of Slovenia, 2014). Countries such as Hungary and the Czech Republic, alongside Germany and Romania, pay significant attention to the problems of IT funding. The Czech Republic in its strategic documents highlights the importance of private-public partnership (Ministry of
Transport - Czech Republic, 2014), while Hungary potentiates the problems of IT terminal funding, and is one of the few countries that distinguishes the technologies of combined road-rail transportation (Hungarian Competition Authority, 2009). In the remaining Danube region countries, the field of IT has a significantly weaker presence in national documents. Countries such as Slovakia, Serbia, Croatia, Ukraine, and Bulgaria pay attention to some of the IT problems, all according to the needs and limitations of the countries (FTTE, 2018). In the end, the least developed countries of the Danube region - Montenegro, Bosnia \& Herzegovina, and Moldova greatly fall behind with IT treatment in their national strategic documents, whose plans often contain poorly translated parts of other countries' planning documents (Tadić et al., 2017). From the aspects of users and service providers, this criterion refers to their attitude towards the quality of the IT system in the countries of the Danube region. The performances of the countries according to this criterion are based on the survey conducted in Transport study for the Danube Region - Study of intermodal transport users' needs in the Danube Region (FTTE, 2018).

\section{C2 - Participation of IT in overall} transportation of countries. It represents a quantitative criterion based on the official national statistics and Eurostat. For the countries with unavailable statistical data regarding the participation of IT in overall transportation, the values are estimated (FTTE, 2018). According to this criterion, the best performing countries are Germany and Austria, while the worst are Croatia, Romania, Slovakia and Bulgaria. 
C3 - Logistics performance index - LPI. This quantitative criterion is a synthetic indicator, developed by the World Bank, and it is used for ranking of countries according to the quality of their logistics. LPI is determined according to six main categories: infrastructure, customs, international shipments, timelines, tracking and tracing, and logistics services quality. According to this criterion, the leading country is Germany, followed by Austria, the Czech Republic and Hungary. The worst-ranked countries are Montenegro, Moldova and Ukraine (World Bank, 2016).

C4 - IT network density. This quantitative criterion represents the ratio of IT terminal number in a country and its surface area. The densest network in the Danube region belongs to Slovenia, which is followed by Austria and Slovakia. The worst-performing countries according to this criteria are Bulgaria and Bosnia \& Herzegovina (FTTE, 2018). From the aspects of users and service providers, this criterion represents their opinions about the development degree of national terminal networks. Evaluation of countries, considering these two stakeholder groups, are based on the results of the survey in (FTTE, 2018).

C5 - Important IT terminals. This quantitative criterion represents the number of IT terminals that apply modern technologies, have a large container throughput (above 100000 TEUs annually) and are the main representatives of IT activity in the country. In countries such as Germany, Austria, Slovenia and the Czech
Republic, a large number of IT terminals (IT activity main representatives) is developed, and regular intermodal lines between terminals are established. Going further to the East, the development degree of IT networks plummets, the absence of adequate IT terminals and technologies is evident, which results in low IT participation in overall transportation of these countries (FTTE, 2018).

C6 - IT users' perception of service offer / IT service providers' competition evaluation. This qualitative criterion is based on the users and service providers survey results for the countries of the Danube region in Transport study for the Danube Region (FTTE, 2018). The users claim that the best service offers are in Germany and the worst in Moldova and Bulgaria. The competition, from the perspective of service providers, is ranked as best in Germany and Austria, and as worst in Moldova and Bosnia \& Herzegovina.

C7 - IT users' perception of IT availability / IT service providers' perception of transportation infrastructure development and connectivity degree. The performances of the countries, according to both stakeholder groups, are based on the survey results in Transport study for the Danube Region (FTTE, 2018). The availability of IT is best-marked in Austria, then in Germany, while the worst performing countries are according to the users in Bosnia \& Herzegovina, Croatia and Serbia. According to the service providers, infrastructure development is best in Austria and Germany, and worst in Bosnia \& Herzegovina. 
Table 1

Criteria for the Assessment of IT Status in the Countries of the Danube Region

\begin{tabular}{|c|c|c|c|}
\hline \multirow{2}{*}{ Criteria } & \multicolumn{3}{|c|}{ Aspect } \\
\hline & Neutral & Service Users & Service Providers \\
\hline C1 & $\begin{array}{l}\text { IT treatment in national } \\
\text { strategic documents }\end{array}$ & $\begin{array}{l}\text { Quality of IT system in the } \\
\text { countries of the Danube region }\end{array}$ & $\begin{array}{l}\text { Quality of IT system in the } \\
\text { countries of the Danube region }\end{array}$ \\
\hline $\mathrm{C2}$ & $\begin{array}{l}\text { Participation of IT in overall } \\
\text { transportation }\end{array}$ & $\begin{array}{l}\text { Participation of IT in overall } \\
\text { transportation }\end{array}$ & $\begin{array}{l}\text { Participation of IT in overall } \\
\text { transportation }\end{array}$ \\
\hline C3 & Rank according to LPI & Rank according to LPI & Rank according to LPI \\
\hline C4 & Density of terminal networks & $\begin{array}{l}\text { Development of terminal } \\
\text { networks }\end{array}$ & $\begin{array}{l}\text { Development of terminal } \\
\text { networks }\end{array}$ \\
\hline C5 & Important IT terminals & Important IT terminals & Important IT terminals \\
\hline C6 & / & Service offer perception & Competition perception \\
\hline C7 & / & Availability of IT & $\begin{array}{l}\text { Development and connectivity } \\
\text { degree of transportation } \\
\text { infrastructure }\end{array}$ \\
\hline
\end{tabular}

In order to assess the status of IT in Danube region countries in the most realistic way, the assessment is executed through six scenarios. The scenarios differ in the observation aspect of IT in the countries of the Danube region, as well as in the significance of the evaluation criteria. In scenario 1, the status of IT and criteria significance is evaluated from the perspective of the users, and the perspective of service providers in scenario 2. Scenario 3 for the evaluation of IT status in the countries considers the aggregated country scores of users and service providers, as well as aggregated criteria weight coefficients. In scenario 4, in the aggregation of scores, the neutral aspect based on strategic documents and available statistics regarding IT is taken into account. In this scenario, all criteria weight coefficients are assumed to be equal. In scenario 5, the scores are also aggregated, but the aggregated criteria weights coefficients are adopted. In scenario 6 , the country scores are fully based on the neutral aspect - only according to the criteria that are derived from strategic documents and official statistics (the first five criteria), with equal criteria weight coefficients.

\section{A Hybrid Fuzzy SWARA \& Fuzzy MARCOS Model}

In this research, for the assessment of IT status in the countries of the Danube region, a novel hybrid MCDM model, based on the methods SWARA and MARCOS in the fuzzy environment, is developed. The SWARA method (Kersuliene et al., 2010) is a simple tool used for criteria weight coefficient extraction, considering decision-maker preferences. This method found its application in the combination with different MCDM methods, in its conventional form and the fuzzy environment as well. In the literature one can find the combinations of SWARA \& TOPSIS (Akcan \& Taş, 2019); SWARA \& PROMETHEE (Shukla et al., 2016); fuzzy SWARA \& fuzzy VIKOR (Rani et al., 2020); fuzzy SWARA \& fuzzy COPRAS (Zarbakhshnia et al., 2018); fuzzy SWARA \& fuzzy MOORA (Mavi et al., 2017); fuzzy SWARA \& CoCoSo (Ulutas et al., 2020); fuzzy Delphi, fuzzy AHP \& fuzzy SWARA (Tadić et al., 2018b), etc.

The MARCOS method is relatively new to the literature (Stević et al., 2020), and is 
proven stable in dynamic environments and insensitive on the change in measurement scales (Stević et al., 2020). By applying the MARCOS method, the relations between the alternatives and the referent values (ideal and anti-ideal solution) are determined, the utility functions of alternatives are calculated, and a compromise ranking of alternatives according to the referent values is derived (Stević \& Brković, 2020). Until now, the MARCOS method has been used in the combination with the FUCOM method (Stević \& Brković, 2020), with CCSD and ITARA methods (Ulutas et al., 2020), but never in the combination with other methods in the fuzzy environment.

\subsection{Algorithmic Steps of the Fuzzy SWARA \& Fuzzy MARCOS Method}

In the following text, the application of the developed fuzzy SWARA \& fuzzy MARCOS
MCDM model is explained. The fuzzy SWARA method is used for the criteria weight coefficient extraction, while the fuzzy MARCOS is used for the assessment of IT status in the countries of the Danube region. The algorithmic steps are explained in the following text:

- Step 1. The application of fuzzy SWARA method for criteria weight coefficient extraction. The algorithmic steps of the fuzzy SWARA method are adapted from the paper (Mavi et al., 2017).

- Step 1.1. Let $n$ be the number of evaluation criteria. Sort the criteria according to the expected importance in descending order.

- Step 1.2. Starting from the second mostimportant criteria, compare the relative importance of every criterion and its predecessor. Criteria comparisons are based on the fuzzy values in Table 2 .

Table 2

Linguistic Terms for Criteria Importance Comparison

\begin{tabular}{|l|c|c|}
\hline Linguistic Term & Abbreviation & Fuzzy Value \\
\hline Equally Significant & ES & $(1,1,1)$ \\
\hline Moderately Less Significant & MLS & $(0.667,1,1.5)$ \\
\hline Less Significant & LS & $(0.4,0.5,0.667)$ \\
\hline Very Less Significant & VLS & $(0.286,0.333,0.4)$ \\
\hline Extremely Less Significant & ELS & $(0.222,0.25,0.286)$ \\
\hline
\end{tabular}

Step 1.3. For every criterion $j$, calculate the fuzzy coefficients $\tilde{e}_{j}$ according to:

$\tilde{e}_{j}=\left(e_{j}^{l}, e_{j}^{m}, e_{j}^{r}\right)=\left\{\begin{array}{c}(1,1,1), j=1 \\ \widetilde{b}_{j}+1, j=2 \ldots n\end{array}\right.$

where $\widetilde{b_{j}}$ is the fuzzy score of the importance of the criterion $j$ relative to its predecessor $j-1$.

Step 1.4. Determine the fuzzy relative criteria weights $\left(\tilde{y}_{j}\right)$ according to: $\tilde{y}_{j}=\left(y_{j}^{l}, y_{j}^{m}, y_{j}^{r}\right)=\left\{\begin{array}{c}(1,1,1), j=1 \\ \frac{\tilde{y}_{j-1}}{\tilde{e}_{j}}=\left(\frac{y_{j-1}^{l}}{e_{j}^{r}}, \frac{y_{j-1}^{m}}{e_{j}^{m}}, \frac{y_{j-1}^{r}}{e_{j}^{l}}\right), j=2 \ldots n\end{array}\right.$

Step 1.5. Calculate the fuzzy criteria weights $\widetilde{w}_{j}$ according to:

$\widetilde{w}_{j}=\left(w_{j}^{l}, w_{j}^{m}, w_{j}^{r}\right)=\frac{\tilde{y}_{j}}{\sum_{z=1}^{n} \tilde{y}_{z}}=\left(\frac{y_{j}^{l}}{\sum_{z=1}^{n} y_{z}^{r}}, \frac{y_{j}^{m}}{\sum_{z=1}^{n} y_{z}^{m}}, \frac{y_{j}^{r}}{\sum_{z=1}^{n} y_{z}^{l}}\right)$

Step 1.6. Defuzzyfy the fuzzy criteria weights $\widetilde{w}_{j}$, and extract the relative criteria 
weight coefficients according to (Kutlu \& Ekmekcioglu 2012):

$w_{j}=\frac{w_{j}^{l}+4 w_{j}^{m}+w_{j}^{r}}{6}$

Step 2. The application of the fuzzy MARCOS method for the ranking of IT in the Danube region countries. In the MARCOS method, the decision matrix consists of the set of alternatives $\left(A_{i}\right)$, the set of criteria $\left(C_{j}\right)$, criteria weight coefficients $\left(w_{j}\right)$, and the alternatives scores according to the criteria. Let $M$ be the number of alternatives and let $a_{i j}$ be the evaluation of the alternative $i$ according to the criterion $j$. In the fuzzy MARCOS method, the evaluation of the alternatives according to the criteria are expressed with linguistic terms which can be converted to the corresponding fuzzy values in the form $a_{i j}=\left(a_{i j}^{l}, a_{i j}^{m}, a_{i j}^{r}\right)$. Linguistic terms and their corresponding fuzzy values for alternative evaluation according to the criteria are shown in Table 3.

\section{Table 3}

Linguistic Terms used for Alternative Evaluation according to the Criteria

\begin{tabular}{|l|c|c|}
\hline Lingusitic term & Abbreviation & Fuzzy value \\
\hline None & N & $(0.1,0.1,1)$ \\
\hline Extremely Poor & EP & $(1,2,3)$ \\
\hline Very Poor & VP & $(2,3,4)$ \\
\hline Poor & P & $(3,4,5)$ \\
\hline Medium Poor & MP & $(4,5,6)$ \\
\hline Medium & M & $(5,6,7)$ \\
\hline Medium Good & MG & $(6,7,8)$ \\
\hline Good & G & $(7,8,9)$ \\
\hline Very Good & VG & $(8,9,10)$ \\
\hline Extremely Good & EG & $(9,10,10)$ \\
\hline
\end{tabular}

Algorithmic steps of the fuzzy MARCOS method are adapted from the paper (Stanković et al., 2020) and explained in the following text.

Step 2.1. Expand the decision matrix with the fuzzy ideal $\left(A^{+}\right)$and the fuzzy anti-ideal solution $\left(A^{-}\right)$:

$$
\begin{gathered}
A^{-} \\
A_{1} \\
A_{2} \\
\vdots \\
A_{m} \\
A^{+}
\end{gathered}\left[\begin{array}{cccc}
C_{1} & C_{2} & \cdots & C_{n} \\
a_{1}^{-} & a_{2}^{-} & \cdots & a_{n}^{-} \\
a_{11} & a_{12} & \cdots & a_{1 n} \\
a_{21} & a_{22} & \cdots & a_{2 n} \\
\vdots & \vdots & \vdots & \vdots \\
a_{m 1} & a_{m 2} & \cdots & a_{m n} \\
a_{1}^{+} & a_{2}^{+} & \cdots & a_{n}^{+}
\end{array}\right]
$$

Let $C^{\max }$ be the set of all maximization criteria and let $C^{\text {min }}$ be the set of all the minimization criteria. The ideal and anti-ideal solutions are determined by using the formulas:

$A^{-}=\min _{1 \leq i \leq M} a_{i j}, j \in C^{\max }$ and $\max _{1 \leq i \leq M} a_{i j}, j \in C^{\text {min }}$,

$A^{+}=\max _{1 \leq i \leq M} a_{i j}, j \in C^{\max }$ and $\min _{1 \leq i \leq M} a_{i j}, j \in C^{\min }$.

Step 2.2. Form the normalized fuzzy matrix $U=\left[u_{i j}\right]_{M \times n}$ according to:

$u_{i j}=\left(u_{i j}^{l}, u_{i j}^{m}, u_{i j}^{r}\right)=\left\{\begin{array}{l}\left(\frac{a_{+}^{l}}{a_{i j}^{l}}, \frac{a_{+}^{m}}{a_{i j}^{m}}, \frac{a_{+}^{r}}{a_{i j}^{r}}\right), j \in C^{\min } \\ \left(\frac{a_{i j}^{l}}{a_{+}^{l},}, \frac{a_{i j}^{m}}{x_{+}^{m}}, \frac{a_{i j}^{r}}{x_{+}^{r}}\right), j \in C^{\max }\end{array}\right.$ 
Step 2.3. Form the weighted matrix $V=\left[v_{i j}\right]_{M \times n}$ by multiplying the elements of the matrix $U$ with the corresponding criteria weight coefficients:

$v_{i j}=\left(v_{i j}^{l}, v_{i j}^{m}, v_{i j}^{r}\right)=\left(w_{j} \cdot u_{i j}^{l}, w_{j} \cdot u_{i j}^{m}, w_{j} \cdot u_{i j}^{r}\right)$

Step 2.4. For every alternative, determine the aggregated fuzzy parameter $S_{i}$ :

$S_{i}=\left(s_{i}^{l}, s_{i}^{m}, s_{i}^{r}\right)=\left(\sum_{j=1}^{n} v_{i j}^{l}, \sum_{j=1}^{n} v_{i j}^{m}, \sum_{j=1}^{n} v_{i j}^{r}\right)$

Step 2.5. Calculate the utility degrees of alternatives $\left(K_{i}^{-}\right.$and $\left.K_{i}^{+}\right)$, where $S_{i}^{-}$and $S_{i}^{+}$ represent the aggregated fuzzy parameter $S_{i}$ values for the anti-ideal and ideal solutions:

$$
\begin{aligned}
& K_{i}^{-}=\left(k_{i}^{-l}, k_{i}^{-m}, k_{i}^{-r}\right)=\frac{s_{i}}{s_{i}^{-}}=\left(\frac{s_{i}^{l}}{s \underline{r}} \frac{s_{i}^{m}}{s \underline{m}}, \frac{s_{i}^{r}}{s_{-}^{l}}\right), \\
& K_{i}^{+}=\left(k_{i}^{+l}, k_{i}^{+m}, k_{i}^{+r}\right)=\frac{s_{i}}{s_{i}^{+}}=\left(\frac{s_{i}^{l}}{s_{+}^{r}}, \frac{s_{i}^{m}}{s_{+}^{m}}, \frac{s_{i}^{r}}{s_{+}^{l}}\right) .
\end{aligned}
$$

Step 2.6. Determine the fuzzy vector $T_{i}$ and the fuzzy value $G$ by using the equations:

$T_{i}=\left(t_{i}^{l}, t_{i}^{m}, t_{i}^{r}\right)=K_{i}^{-} \oplus K_{i}^{+}=$

$=\left(k_{i}^{-1}+k_{i}^{+1}, k_{i}^{-\mathrm{m}}+k_{i}^{+\mathrm{m}}, k_{i}^{-\mathrm{r}}+k_{i}^{+\mathrm{r}}\right)$,

$G=\left(g^{l}, g^{m}, g^{r}\right)=\max _{1 \leq i \leq M} T_{i}$,

where $G^{\text {crisp }}$, the defuzzyfied value of $G$, is calculated according to the formula (4).

Step 2.7. Determine the utility functions of alternatives relative to the ideal and antiideal solution:

$$
\begin{aligned}
& f\left(K_{i}^{+}\right)=\frac{K_{i}^{-}}{G^{\text {crisp }}}=\left(\frac{k_{i}^{-l}}{G^{\text {crisp }}}, \frac{k_{i}^{-m}}{G^{\text {crisp }}}, \frac{k_{i}^{-r}}{G^{\text {crisp }}}\right), \\
& f\left(K_{i}^{-}\right)=\frac{K_{i}^{+}}{G^{\text {crisp }}}=\left(\frac{k_{i}^{+l}}{G^{\text {crisp }}}, \frac{k_{i}^{+m}}{G^{\text {crisp }}}, \frac{k_{i}^{+r}}{G^{\text {crisp }}}\right) .
\end{aligned}
$$

Step 2.8. Defuzzyfy the values $K_{i}^{-}, K_{i}^{+}, f\left(K_{i}^{-}\right.$ ), and $f\left(K_{i}^{+}\right)$by applying the formula (4). Assess the final alternative scores $\left(F_{i}\right)$ according to the derived crisp values by using the formula:

$F_{i}=\frac{K_{i}^{+}+K_{i}^{-}}{1+\frac{1-f\left(K_{i}^{+}\right)}{f\left(K_{i}^{+}\right)}+\frac{1-f\left(K_{i}^{-}\right)}{f\left(K_{i}^{-}\right)}}$

Step 2.9. Rank the alternatives according to the parameter $F_{i}$ in descending order. Alternatives with greater $F_{i}$ value are better.

\subsection{Ranking of IT Status in the Countries of the Danube Region}

By applying the developed hybrid fuzzy SWARA \& fuzzy MARCOS model, the countries of the $D$ anube region are ranked according to the status of their IT. The ranking is done according to the aforementioned seven criteria, through six scenarios.

The first phase of the developed hybrid model refers to criteria weight coefficient extraction by applying the fuzzy SWARA method. The perception of criteria importance, according to the users and service providers, is shown in Table 4. Criteria importance values are determined according to the expert opinions of authors and are based on their experience and the analysis conducted in the project (FTTE, 2018). According to this, by applying the formulas (1)-(4), the criteria weight coefficients, from the aspects of users and service providers (and overall, aggregated), are derived (Table 5). 


\section{Table 4}

Evaluation of Criteria Importance according to the Users and Service Providers

\begin{tabular}{|c|c|c|c|c|}
\hline & \multicolumn{2}{|c|}{ Service Users } & \multicolumn{2}{c|}{ Service Providers } \\
\hline & Criteria & Linguistic Term & Criteria & Linguistic Term \\
\hline \multirow{3}{*}{} & C6 & ES & C7 & ES \\
\cline { 2 - 5 } & C7 & MLS & C4 & ES \\
\cline { 2 - 5 } & C1 & ES & C2 & MLS \\
\cline { 2 - 5 } & C4 & ES & C6 & MLS \\
\cline { 2 - 5 } & C5 & LS & C5 & LS \\
\cline { 2 - 5 } & C2 & VLS & C3 & ES \\
\cline { 2 - 5 } & C3 & ES & & \\
\hline
\end{tabular}

Table 5

Criteria Weight Coefficients

\begin{tabular}{|c|c|c|c|}
\hline Criteria & Service Users & Service Providers & Aggregated \\
\hline C1 & 0.123 & 0.024 & 0.073 \\
\hline C2 & 0.031 & 0.125 & 0.078 \\
\hline C3 & 0.016 & 0.012 & 0.014 \\
\hline C4 & 0.061 & 0.247 & 0.154 \\
\hline C5 & 0.041 & 0.034 & 0.038 \\
\hline C6 & 0.483 & 0.065 & 0.274 \\
\hline C7 & 0.245 & 0.494 & 0.369 \\
\hline
\end{tabular}

The second phase of the model refers to the application of the fuzzy MARCOS method, through the steps (5)-(17), for assessing the status of IT in the countries of the Danube region. All countries are evaluated according to all seven criteria, from a neutral, user and service provider perspective (Table 6). The scores are the results of expert opinions of the authors, quantitative data and statistics regarding IT, and the conducted research in the project (FTTE, 2018). Based on Table 3 , the linguistic terms used for evaluating countries according to the criteria are transformed into corresponding fuzzy values.

\section{Table 6}

The Evaluation of Countries according to the Criteria (Neutral/Service Users/Service Providers)

\begin{tabular}{|c|c|c|c|c|c|c|c|}
\hline Country & $\mathrm{C} 1$ & $\mathrm{C} 2$ & $\mathrm{C} 3$ & $\mathrm{C} 4$ & $\mathrm{C} 5$ & C6 & $\mathrm{C} 7$ \\
\hline Austria & G/EG/EG & $\mathrm{MG} / * /^{*}$ & $\mathrm{EG} / * / *$ & VG/G/EG & $\mathrm{EG} / * / *$ & */G/EG & $* / \mathrm{EG} / \mathrm{EG}$ \\
\hline $\begin{array}{l}\text { Bosnia \& } \\
\text { Herzegovina }\end{array}$ & $\mathrm{M} / \mathrm{MP} / \mathrm{P}$ & $\mathrm{EP} /{ }^{*}{ }^{*}$ & $\mathrm{EP} /{ }^{*} / *$ & $\mathrm{P} / \mathrm{P} / \mathrm{P}$ & $\mathrm{N} /{ }^{*} / *$ & $* / \mathrm{P} / \mathrm{EP}$ & $* / \mathrm{VP} / \mathrm{P}$ \\
\hline Bulgaria & $\mathrm{M} / \mathrm{M} / \mathrm{MG}$ & $\mathrm{EP} / * / *$ & $\mathrm{VP} /{ }^{*} / *$ & $\mathrm{EP} / \mathrm{MG} / \mathrm{MG}$ & $\mathrm{N} /{ }^{*} / *$ & */P/MG & ${ }^{*} / \mathrm{M} / \mathrm{MG}$ \\
\hline Montenegro & $\mathrm{MP} / \mathrm{M} / \mathrm{M}$ & $\mathrm{EP} / *{ }^{*}$ & $\mathrm{EP} / *{ }^{*}$ & $\mathrm{M} / \mathrm{MP} / \mathrm{MP}$ & $\mathrm{N} /{ }^{*} /{ }^{*}$ & */M/P & */P/MP \\
\hline Czech Republic & G/VG/MG & $\mathrm{VP} /{ }^{*}{ }^{*}$ & $\mathrm{G} /{ }^{*} / *$ & MG/VG/G & $\mathrm{MP} / * / *$ & */VG/G & */M/G \\
\hline Croatia & $\mathrm{MG} / \mathrm{MG} / \mathrm{M}$ & $\mathrm{VP} /{ }^{*} / *$ & $\mathrm{MP} / * / *$ & $\mathrm{M} / \mathrm{MP} / \mathrm{MP}$ & $\mathrm{EP} / * / *$ & */MG/MP & $* / \mathrm{VP} / \mathrm{MP}$ \\
\hline Hungary & $\mathrm{M} / \mathrm{MG} / \mathrm{G}$ & $\mathrm{EP} /{ }^{*} / *$ & $\mathrm{M} /{ }^{*} / *$ & $\mathrm{MP} / \mathrm{G} / \mathrm{MG}$ & $\mathrm{P} /{ }^{*} / *$ & */G/MG & ${ }^{*} / \mathrm{M} / \mathrm{G}$ \\
\hline Moldova & $\mathrm{MP} / \mathrm{M} / \mathrm{P}$ & $\mathrm{MP} / * / *$ & $\mathrm{EP} /{ }^{*} / *$ & $\mathrm{MP} / \mathrm{MP} / \mathrm{P}$ & $\mathrm{N} /{ }^{*} / *$ & $* / \mathrm{P} / \mathrm{EP}$ & */P/MP \\
\hline Germany & EG/EG/EG & $\mathrm{EG} / * / *$ & $\mathrm{EG} / * / *$ & G/VG/EG & $\mathrm{VG} / * / *$ & ${ }^{*} / \mathrm{EG} / \mathrm{EG}$ & $* / \mathrm{G} / \mathrm{VG}$ \\
\hline Romania & $\mathrm{VG} / \mathrm{M} / \mathrm{MP}$ & $\mathrm{EP} / *{ }^{*}$ & $\mathrm{P} /{ }^{*} / *$ & $\mathrm{VP} / \mathrm{M} / \mathrm{MP}$ & $\mathrm{MP} / * / *$ & */MP/MP & */MP/M \\
\hline Slovakia & G/G/MG & $\mathrm{EP} / * / *$ & $\mathrm{M} /{ }^{*} / *$ & $\mathrm{VG} / \mathrm{M} / \mathrm{M}$ & $\mathrm{P} /{ }^{*} / *$ & */M/VG & ${ }^{*} / \mathrm{M} / \mathrm{MG}$ \\
\hline Slovenia & $\mathrm{MG} / \mathrm{MG} / \mathrm{G}$ & $\mathrm{P} /{ }^{*} / *$ & $\mathrm{MP} / * / *$ & EG/MG/MG & $\mathrm{P} / * / *$ & $* / \mathrm{M} / \mathrm{G}$ & ${ }^{*} / \mathrm{M} / \mathrm{MG}$ \\
\hline Serbia & $\mathrm{MP} / \mathrm{MP} / \mathrm{MP}$ & $\mathrm{EP} / * / *$ & $\mathrm{VP} /{ }^{*} / *$ & $\mathrm{VP} / \mathrm{P} / \mathrm{MP}$ & $\mathrm{N} / *^{*} *$ & */P/MP & ${ }^{*} / \mathrm{VP} / \mathrm{MP}$ \\
\hline Ukraine & $\mathrm{P} / \mathrm{MG} / \mathrm{MG}$ & $\mathrm{M} /{ }^{*} / *$ & $\mathrm{EP} /{ }^{*} / *$ & $\mathrm{P} / \mathrm{MG} / \mathrm{MG}$ & $\mathrm{P} /{ }^{*} / *$ & */M/M & */MP/G \\
\hline
\end{tabular}


The assessment of IT status in the countries of the Danube region is executed through six scenarios that are described in the previous chapter. Scenario 1 takes into account the criteria weight coefficients from the users' perspectives, while in scenario 2, they are based on the aspect of service providers. Scenario 3 and scenario 5 use the aggregated criteria weight coefficients, while in scenario 4 , all criteria weight coefficients are equal (0.143). Scenario 6 also takes into account equal criteria weight coefficients, but since only the first five criteria are considered, the criteria weight coefficients are equal to 0.2 . The output results of the hybrid MCDM model, for all the scenarios, are presented in Table 7.

Table 7

Output Results of the Hybrid MCDM Model

\begin{tabular}{|l|c|c|c|c|c|c|}
\hline Country & Scenario 1 & Scenario 2 & Scenario 3 & Scenario 4 & Scenario 5 & Scenario 6 \\
\hline Austria & 0.760 & 0.896 & 0.931 & 0.874 & 0.925 & 0.806 \\
\hline $\begin{array}{l}\text { Bosnia \& } \\
\text { Herzegovina }\end{array}$ & 0.119 & 0.107 & 0.120 & 0.100 & 0.123 & 0.081 \\
\hline Bulgaria & 0.202 & 0.347 & 0.358 & 0.147 & 0.318 & 0.070 \\
\hline Montenegro & 0.232 & 0.174 & 0.221 & 0.141 & 0.226 & 0.093 \\
\hline Czech Republic & 0.612 & 0.502 & 0.602 & 0.491 & 0.592 & 0.395 \\
\hline Croatia & 0.285 & 0.198 & 0.253 & 0.249 & 0.262 & 0.214 \\
\hline Hungary & 0.472 & 0.435 & 0.507 & 0.321 & 0.485 & 0.214 \\
\hline Moldova & 0.157 & 0.170 & 0.178 & 0.141 & 0.180 & 0.119 \\
\hline Germany & 0.870 & 0.881 & 0.941 & 0.944 & 0.930 & 0.919 \\
\hline Romania & 0.238 & 0.239 & 0.287 & 0.256 & 0.283 & 0.214 \\
\hline Slovakia & 0.343 & 0.353 & 0.446 & 0.420 & 0.475 & 0.344 \\
\hline Slovenia & 0.342 & 0.409 & 0.469 & 0.426 & 0.492 & 0.363 \\
\hline Serbia & 0.120 & 0.178 & 0.179 & 0.110 & 0.173 & 0.070 \\
\hline Ukraine & 0.315 & 0.486 & 0.438 & 0.241 & 0.406 & 0.161 \\
\hline
\end{tabular}

\section{Result Analysis}

The final scores of Danube region countries, according to the status of IT, are assessed by applying the developed hybrid MCDM model. For simpler result analysis, the countries are classified into five categories, micro-regions according to their scores (Table 8). Category boundaries are defined so that their range increases by going from the best to lower categories (micro-regions). Developing countries lack in understanding of the IT importance, as well as in key elements for its development. Their strategic documents have large gaps and give to much room for different interpretations, so it is very difficult to perceive the differences in the level of their IT development. On the contrary, the developed countries dedicate their attention to a wide set of IT-related problems, so the differences can be noticed in minor details.

According to the aforementioned, the category (micro-region) A consists of the countries whose status of IT is at the highest level, that is, of those that have the value of $F_{i}$ greater than 0.85 . Micro- 
region $\mathrm{B}$ consists of the countries with very good status of IT, with the value of $F_{i}$ between 0.7 and 0.85 . The countries with moderately good status of IT form the category, micro-region $\mathrm{C}$, with the value of $F_{i}$ between 0.5 and 0.7 . They are followed by the countries with poor IT status (micro-region D), with the value of $F_{i}$ between 0.25 and 0.5 , and by the countries with very poor status of IT (micro-region E), with the value of $F_{i}$ below 0.25 . The grouping of the Danube region countries into micro-regions, according to the status of their IT, is shown in Table 9.

\section{Table 8}

Defined Categories of Countries (Micro-regions) according to the Status of IT

\begin{tabular}{|l|c|c|c|c|}
\hline \multirow{2}{*}{ Status of IT } & \multirow{2}{*}{$\begin{array}{c}\text { Category, } \\
\text { Micro-region }\end{array}$} & \multicolumn{2}{|c|}{ F } & \multirow{2}{*}{ Color } \\
\cline { 3 - 4 } Excellent Status & A & 0.85 & 1 & \\
\hline Very Good Status & B & 0.7 & 0.85 & \\
\hline Moderately Good Status & C & 0.5 & 0.7 & \\
\hline Poor Status & D & 0.25 & 0.5 & \\
\hline Very Poor Status & E & 0 & 0.25 & \\
\hline
\end{tabular}

\section{Table 9}

Micro-regions of the Danube Region according to the Status of IT

\begin{tabular}{|c|c|c|c|c|c|c|}
\hline Country & Scenario 1 & Scenario 2 & Scenario 3 & Scenario 4 & Scenario 5 & Scenario 6 \\
\hline Austria & B & A & A & A & A & B \\
\hline $\begin{array}{l}\text { Bosnia \& } \\
\text { Herzegovina }\end{array}$ & E & $\mathrm{E}$ & $\mathrm{E}$ & $\mathrm{E}$ & E & $\mathrm{E}$ \\
\hline Bulgaria & E & $\mathrm{D}$ & $\mathrm{D}$ & E & $\mathrm{D}$ & E \\
\hline Montenegro & $\mathrm{E}$ & $\mathrm{E}$ & E & $\mathrm{E}$ & E & E \\
\hline Czech Republic & $\mathrm{C}$ & $\mathrm{C}$ & $\mathrm{C}$ & $\mathrm{D}$ & $\mathrm{C}$ & $\mathrm{D}$ \\
\hline Croatia & $\mathrm{D}$ & $\mathrm{E}$ & $\mathrm{D}$ & $\mathrm{E}$ & $\mathrm{D}$ & $\mathrm{E}$ \\
\hline Hungary & $\mathrm{D}$ & $\mathrm{D}$ & $\mathrm{C}$ & $\mathrm{D}$ & $\mathrm{D}$ & $\mathrm{E}$ \\
\hline Moldova & E & $\mathrm{E}$ & E & E & E & $\mathrm{E}$ \\
\hline Germany & A & A & A & A & A & A \\
\hline Romania & $\mathrm{E}$ & $\mathrm{E}$ & $\mathrm{D}$ & $\mathrm{D}$ & $\mathrm{D}$ & E \\
\hline Slovakia & $\mathrm{D}$ & $\mathrm{D}$ & $\mathrm{D}$ & $\mathrm{D}$ & $\mathrm{D}$ & $\mathrm{D}$ \\
\hline Slovenia & $\mathrm{D}$ & $\mathrm{D}$ & $\mathrm{D}$ & $\mathrm{D}$ & $\mathrm{D}$ & $\mathrm{D}$ \\
\hline Serbia & $\mathrm{E}$ & $\mathrm{E}$ & $\mathrm{E}$ & E & E & E \\
\hline Ukraine & $\mathrm{D}$ & $\mathrm{D}$ & $\mathrm{D}$ & E & D & E \\
\hline
\end{tabular}


The grouping of the Danube region countries into micro-regions varies significantly in the scenarios (Fig. 1), but certain patterns do exist. Germany is classified to the microregion with the best IT status in every scenario and is followed by Austria which is, in scenarios 1 (users aspect) and 6 (neutral aspect based on quantitative data), classified into the micro-region $\mathrm{B}$, and in the category of the best IT status (microregion A) in other scenarios. The Czech Republic is in four scenarios (scenarios 1, 2, 3 and 5) classified into the micro-region C, with moderately good IT status, and in the scenarios 4 (aggregated scores) and 6 (neutral aspect based on quantitative data) into the micro-region $\mathrm{D}$ with poor IT status. In every scenario, Slovakia and Slovenia are classified into this micro-region as well. Ukraine is, in the scenarios based on the perspectives of users, service providers, their aggregated scores, and in scenario 5 (aggregated scores of users, service providers, and the neutral aspect, with aggregated criteria weight coefficients), classified into the micro-region $\mathrm{D}$, and in the remaining two scenarios into the category with very poor status of ITmicro-region E. Romania, Bulgaria, and Croatia, in half of the scenarios, are classified into the category with poor status of IT (Romania in scenarios 3, 4, and 5; Bulgaria in the scenarios 2, 3, and 5; Croatia in the scenarios 1,3 , and 5), and in another half of the scenarios into the category with very poor status of IT (Romania in scenarios 1, 2, and 6; Bulgaria in the scenarios 1, 4, and 6; Croatia in the scenarios 2, 4, and 6). Hungary is the country whose category varies the most in the scenarios - in four scenarios (users' aspect, service providers' aspect, and the scenarios that aggregate the scores of all three aspects) is classified into the category with poor status of IT (micro-region D), in the scenario with aggregated scores of users and providers into the category with moderately good status of IT (micro-region $\mathrm{C}$ ), and in the scenario 6 (neutral aspect based on quantitative data) into the category with very poor status of IT (micro-region E). Bosnia \& Herzegovina, Montenegro, Serbia and Moldova, in all the scenarios, are classified into the category with very poor status of IT - micro-region $\mathrm{E}$.

The results provide a good insight into the reality regarding the status of IT. Germany and Austria are the countries that are treating their IT on an excellent level, although a slight difference between them exists. This difference can be noticed in the greater IT involvement in the overall transportation of Germany than the IT involvement of Austria. Furthermore, Germany is, according to the users, slightly better performing on some of the criteria. The Czech Republic is the thirdranked, and in comparison with Germany and Austria, it falls behind with performance on the criteria C2, C3, and C5. Hungary, Slovenia, and Slovakia, then Bulgaria, Croatia, Romania, and Ukraine, fall back greatly, especially in terms of IT participation in overall transportation and the number of important IT terminals. In the end, Bosnia \& Herzegovina, Montenegro, Serbia, and Moldova, have a serious slower pace in comparison with the countries classified in higher categories. These countries perform especially poorly according to the criteria C2, C3, C6, and C7. 


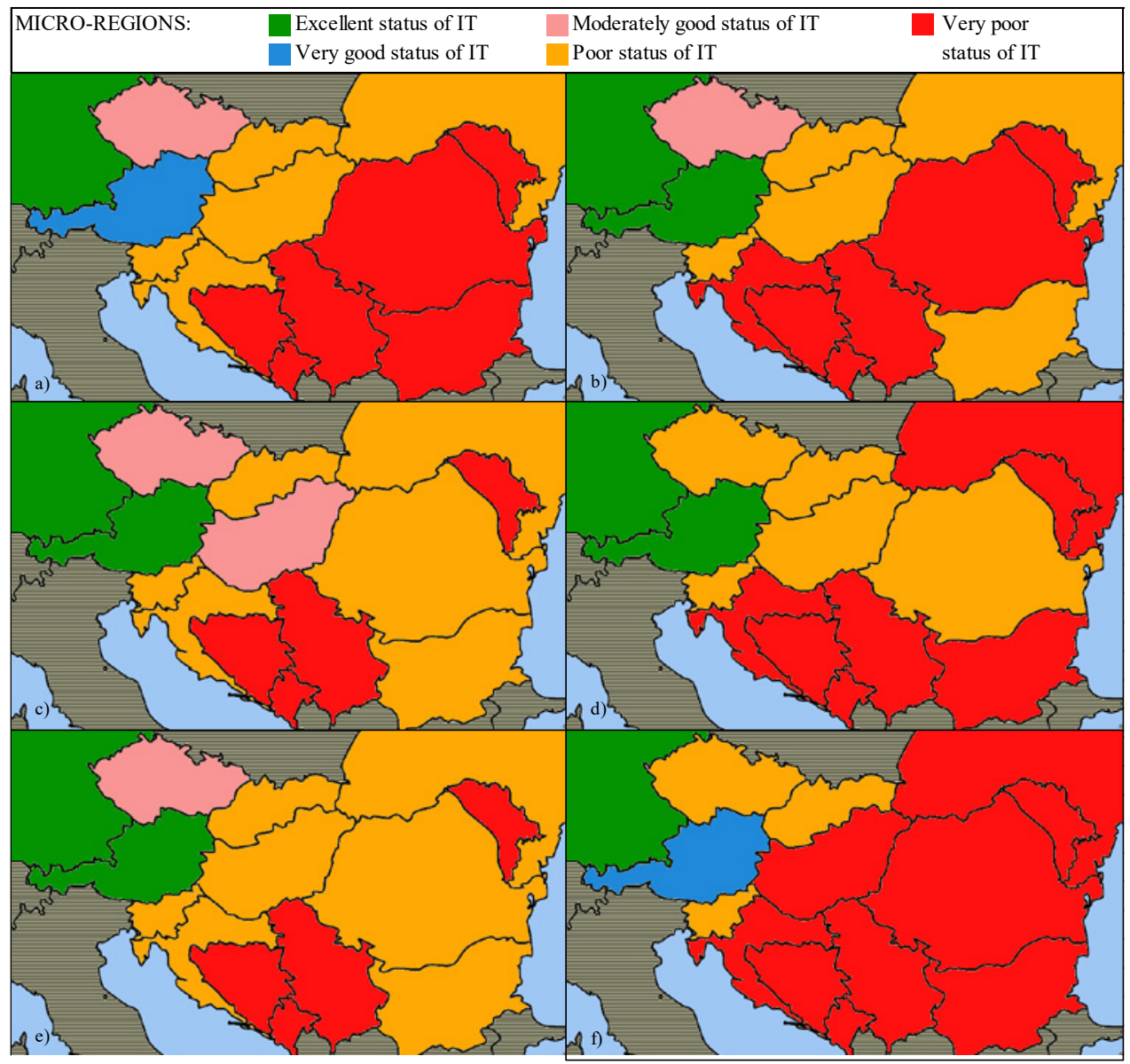

Fig. 1.

The Classification of Danube Region Countries according to the Status of IT: a) Scenario 1; b) Scenario 2; c) Scenario 3; d) Scenario 4; e) Scenario 5; f) Scenario 6

\section{Conclusion}

This research assessed the status of IT in Danube region countries. Besides the aforementioned, the scientific contribution of the research is that the assessment is done according to seven criteria and six scenarios through the application of a hybrid fuzzy SWARA \& fuzzy MARCOS MCDM model. The scenarios differ in the aspect of the IT and the significance of the criteria. The aspects of users and service providers, as well as a neutral aspect, based on strategic documents of the countries and available empirical data and statistics, are considered. According to the results, the countries are classified into five categories - microregions.

The results indicate that the status of IT is best in Germany, followed by Austria. Furthermore, the status of IT in the Czech 
Republic is moderately good, and into this category (micro-region) Hungary is classified according to the scenario that considers the aggregated scores of users and service providers. Slovenia and Slovakia follow up, while other countries fall behind greatly. The direction of future research could be in the identification of the differences in the perception of IT quality from the aspects of users and service providers, overall and according to individual criteria - quality parameters as well. Aside from this, the research that analyzes the necessary measures that would stimulate IT development in individual countries is insufficient. Since the countries have significant differences, different research levels and approaches are required for defining goals, measures, and development directions of their IT systems.

\section{References}

AECOM Ingenieria SRL. 2014. Romania General Transport Master Plan.

Akcan, S.; Taş, M. A. 2019. Green supplier evaluation with SWARA-TOPSIS integrated method to reduce ecological risk factors, Environmental Monitoring and Assessment 191(12): 736-757.

Barysiene, J. 2012. A multi-criteria evaluation of container terminal technologies applying the COPRAS-G method, Transport 27(4): 364-372.

BMVIT. 2011. National Action Plan, Danube Navigation (NAP). Available from Internet: <https://www.bmvit. gv.at/en/verkehr/waterways/nap.html>. Accessed on: 17.09.2020.

Caris, A.; Macharis, C.; Janssens, G. K. 2013. Decision support in intermodal transport: A new research agenda, Computers in Industry 64(2): 105-112.
EC - European Commission. 2011. White Paper: Roadmap to a Single European Transport Area Towards a Competitive and Resource Efficient Transport System. Available from Internet: <https://ec.europa. eu/transport/sites/transport/files/themes/strategies/ doc/2011_white_paper/white-paper-illustratedbrochure_en. Pdf $>$.

ECMT - European Conference of Ministers of Transport. 2001. Terminology on combined transport. Available from Internet: <http://www.unece.org/ fileadmin/DAM/trans/wp24/documents/term.pdf>.

Eftestöl-Wilhelmsson, E.; Bask, A.; Rajahonka, M. 2014. Intermodal transport research: A law and logistics literature review with EU focus, European Transport Law 49(6): 609-674.

Eng-Larsson, F.; Kohn, C. 2012. Modal shift for greener logistics - the shipper's perspective, International Journal of Physics Distribution \& Logistics Management 42(1): 36-59.

Fang, X.; Cao, C.; Chen, Z.; Chen, W.; Ni, L.; Ji, Z.; Gan, J. 2019. Using mixed methods to design service quality evaluation indicator system of railway container multimodal transport, Science Progress 103(1): 1-27.

Federal Ministry of Transport, Building and Urban Development (FMoTBD). 2010. Freight Transport and Logistics Action Plan - Logistics Initiative for Germany.

FTTE. 2018. Transport study for the Danube Region Study of intermodal transport users' needs in the Danube Region. Faculty of Transport and Traffic Engineering, University of Belgrade, Belgrade, Serbia. The study is co-founded by EU fonds (ERDF and IPA II).

Gharehgozli, A.; De Vries, H.; Decrauw, S. 2019. The role of standardisation in European intermodal transportation, Maritime Business Review 4(2): 1-19.

Hungarian Competition Authority. 2009. Merger in Combined Road-Railway Transportation Services. 
Islam, D.M.Z.; Ricci, S.; Nelldal, B.L. 2016. How to make modal shift from road to rail possible in the European transport market, as aspired to in the EU Transport White Paper 2011, European Transport Research Review 8(3): 18.

Kersuliene, V.; Zavadskas, E. K.; Turskis, Z. 2010. Selelection of rational dispute resolution method by applying new step-wise weight assessment ratio analysis (SWARA), Journal of Business Economics and Management 11(2): 243-258.

Kutlu, A. C.; Ekmekcioglu, M. 2012. Fuzzy failure modes and effects analysis by using fuzzy TOPSIS/based fuzzy AHP, Expert Systems with Applications 39(1): 61-67.

Mavi, R.; Goh, M.; Zarbakhshnia, N. 2017. Sustainable third-party reverse logistic provider selection with fuzzy SWARA and fuzzy MOORA in plastic industry, The International Journal of Advanced Manufacturing Technology 91(5-8): 2401-2418.

Ministry of Infrastructure, Republic of Slovenia. 2014. Transport Development Strategy in the Republic of Slovenia.

Ministry of Transport, Czech Republic. 2014. The Transport Policy of the Czech Republic for 2014 - 2020 with the prospect of 2050 .

Rani, P.; Mishra, A.R.; Mardani, A.; Cavallaro, F.; Štreimikiene, D.; Khan, S.A.R. 2020. Pythagorean fuzzy SWARA-VIKOR framework for performance evaluation on solar panel selection, Sustainability 12(10): 4278-4295.

Shukla, S.; Mishra, P. K.; Jain, R.; Yadav, H. C. 2016. An integrated decision making approach for ERP system selection using SWARA and PROMETHEE method, International Journal of Intelligent Enterprise 3(2): 120-147.

Stanković, M.; Stević, Ž.; Kumar Das, D.; Subotić, M.; Pamučar, D. 2020. A new fuzzy MARCOS method for road traffic risk analysis, Mathematics $8:$ 457-475.
Stević, Ž.; Brković, N. 2020. A novel integrated FUCOM-MARCOS model for evaluation of human resources in a transport company, Logistics 4(4): 1-14.

Stević, Ž.; Pamučar, D.; Puška, A.; Chatterjee, P. 2020. Sustainable supplier selection in healthcare industries using a new MCDM method: Measurement of alternatives and ranking according to compromise solution (MARCOS), Computers \& Industrial Engineering 140: 1-33.

Suarez-Aleman, A.; Trujillo, L.; Medda, F. 2014. Short sea shipping as intermodal competitor: A theoretical analysis of European transport policies, Maritime Policy \& Management 42(4): 1-18.

Tadić, S.; Zečević, S. 2012. Development of intermodal transport and logistics in Serbia, International Journal for Traffic and Transport Engineering 2(4): 380-390.

Tadić, S.; Zečević, S.; Milenković, D. 2017. Intermodal transport treatment in developed and developing countries, Tehnika 67(6): 897-902.

Tadić, S.; Zečević, S.; Milenković, D. 2018a. Problems regarding intermodal transport in the Danube Region. In Proceedings of the 4th International Conference on Traffic and Transport Engineering, ICTTE 2018, Belgrade, Serbia, 483-489.

Tadić, S.; Zečević, S.; Krstić, M. 2018b. Assessment of political city logistics initiatives sustainability, Transportation Research Procedia 30: 285-294.

Ulutas, A.; Bulent Karakus, C.; Topal, A. 2020. Location selection for logistics center with fuzzy SWARA and CoCoSo methods, Journal of Intelligent and Fuzzy Systems 38(1): 1-17.

Ulutas, A.; Karabasevic, D.; Popovic, G., Stanujkic, D.; Nguyen, P.T.; Karakoy, C. 2020. Development of a novel integrated CCSD-ITARA-MARCOS decision-making approach for stackers selection in a logistics system, Mathematics 8: 1672-1687.

\section{jitte 390}


Van den Berg, R.; De Langen, P.W. 2014. Assessing the intermodal value proposition of shipping lines: Attitudes of shippers and forwarders, Maritime Economics \& Logistics 17(1): 32-51.

World Bank. 2016. Logistics performance index. Available from Internet: <https://lpi.worldbank.org >.

Zarbakhshnia, N.; Soleimani, H.; Ghaderi, H. 2018. Sustainable third-party reverse logistics provider evaluation and selection using fuzzy SWARA and developed fuzzy COPRAS in the presence of risk criteria, Applied Soft Computing 65: 307-319.

Zečević, S. 2009. Logistics centres and freight villages [in Serbian: Robni terminali i robno-transportni centri]. University of Belgrade, Faculty of Transport and Traffic Engineering, Belgrade, Serbia, 280p. 